\title{
PERFORMANCE OF PROGNOSTIC SCORES IN AKI POPULATION IN ICU
}

\section{Nephrology}

\section{Dr. Rahul sood}

Consultant incharge Department of nephrology Kidney hospital and lifeline medical institutions, Jalandhar

Dr Jasmin das*

Associate Professor Dept. of Nephrology Christian Medical College and hospital, Ludhiana *Corresponding Author

Dr Ashu mathai Professor Department of anesthesiology Believer's Hospital, Kerala

\begin{abstract}
Acute kidney injury in hospitalized patients is associated with high mortality rates and increased length of hospital stay. Prognostication of patients with AKI is of immense value in making decisions regarding the optimal type and intensity of treatment, patient selection, and clinical discussions on prognosis and in assessment of the quality of an ICU. Prognostic scores are comprised of relevant clinical and laboratory variables of patients associated to the clinical endpoint. There are limited studies that have evaluated which prognostic score may be used in patients with AKI. Studies have shown that APACHE II underestimates hospital mortality whereas AKI specific Liano score has better statistical correlation with mortality. Materials and methods: All patients admitted to the ICU fulfilling the inclusion criteria during the study period were recruited and evaluated for AKI by both RIFLE and AKI criteria. Prognostic scores, APACHE II and Liano were used in predicting hospital mortality. Assessment of score performance was made through analysis of the discrimination and calibration using area under a receiver operating characteristic curve (AUROC) and Hosmer and Lemeshow goodness of fit test.

Results: Mean APACHE II score was higher in AKI subjects compared to non AKI and was statistically significant and it increased with the severity of AKI. The AUROC for APACHE II score was 0.739 and 0.706 for AKIN and RIFLE respectively and signifies APACHE II score increases with AKI. An AUROC curve of prognostic scores for predicting mortality was 0.677 and 0.639 for Liano and APACHE II respectively and on comparison showed insignificant $p$ value (0.6331). Assessment of calibration showed that the calibration was good for specific score.

Conclusion: Assessment of performance of both the prognostic scores APACHE II and Liano had poor discrimination but calibration was good for Liano model.

\section{KEYWORDS}

Acute kidney injury, RIFLE, AKIN, APACHE II, Liano Score, AUROC
\end{abstract}

\section{INTRODUCTION}

Acute kidney injury (AKI) in hospitalized patients is associated with high mortality rates and increased length of hospital stay ${ }^{[1]}$. Evaluation of prognosis is a routine in medical practice. Selection of patients, type and intensity of treatments, in addition to other decisions related to patient care are influenced by the prognostic outcome. Risk stratification and prediction of outcome in AKI patients in the ICU (intensive care unit) are important determinants for improvement of patient care.

APACHE II (Acute Physiology and Chronic Health evaluation) and SOFA (Sequential Organ Failure Assessment), as well as a number of other "general" prognostic indexes, are logistic models that included large numbers of patients ${ }^{[2,3]}$. Acute kidney injury has been a significant component of critical care scoring systems constituting $20 \%$ and $16.6 \%$ of the APACHE II ${ }^{[3]}$ and SOFA scores ${ }^{[4]}$ respectively. In some studies, APACHE II score predicted mortality in patients with ARF ${ }^{[5]}$ It has been suggested that several clinical conditions eg. assisted respiration, hypotension, oliguria, coma and jaundice have a detrimental effect on outcome. Previous health status, premorbid illnesses and age also seem to affect the outcome. ${ }^{[6]}$

Liano and coworkers found that the linear regression model's receiver operating characteristic (ROC) curve was better than the logistic regression model to predict hospital mortality. They also found that there were no survivors above a discriminant score of 0.9 , and at this level, the sensitivity of the score was $28 \%$, the specificity $100 \%$, and the positive predictive value was $100 \%$. They also evaluated several general scores and four kidney specific severity scores (Rasmussen's, Lohr's, Schaefer's and Liano's) in patients of acute renal failure on renal replacement therapy and found Liano's score to have the highest area under the receiver operating curve(AUROC). Patients in the highest quintile of Liano's score had near- $100 \%$ mortality.

\section{AIMSAND OBJECTIVES}

To evaluate the performance of the APACHE II and Liano scores in predicting in-hospital mortality among patients with acute kidney injury in ICU.

\section{MATERIALAND METHODS}

This is a prospective observational cohort study conducted in department of Nephrology in Christian Medical College and Hospital, Ludhiana over a period of one year from 2015 to 2016.

\section{Inclusion criteria}

- All patient admitted in ICU with wide variety of medical \& surgical disorders necessitating ICU care, after obtaining due consent.

\section{Exclusion Criteria}

- Age less than 18 years

- Chronic kidney disease (CKD)

- Patients with ICU stay less than $48 \mathrm{~h}$

- Patients unwilling to participate in the study or to give informed consent.

Demographic data was collected for all the patients admitted in ICU fulfilling the inclusion criteria. These patients were followed up during ICU stay and until discharge from hospital.

Patients were evaluated daily by using the AKIN and RIFLE criteria after admission, until discharge from the ICU, and the maximum AKIN and RIFLE within ICU hospitalization were recorded. The worst classification during the patient's ICU stay was used.

Prognostic scores (APACHE II and Liano) were used in predicting hospital mortality in patients diagnosed to have AKI as per RIFLE and AKIN in the study period. APACHE II score was calculated from first 24hr of ICU admission [QxMD calculate use for score calculation] \& Liano score was assessed from first $24 \mathrm{hr}$ of renal replacement therapy (RRT) initiation

\section{Statistical Analysis}

Comparisons between RIFLE classes or AKIN stages were performed using analysis of variance and the chi-square test for continuous variables and categorical variables, respectively. Assessment of score performances was made through analysis of the discrimination and calibration by using the receiver operating characteristic curve (AUROC) curve and Hosmer \& Lemeshow goodness of fit test. A twotailed $P$ value $<0.05$ was considered significant. All statistical analysis was performed using SPSS, version 21.0. Armonk, NY: IBM corp. 
RESULTS

In our study 360 patients out of 583 patients who got admitted in ICU were included.

Table 1:Baseline characteristics of subjects

\begin{tabular}{|c|c|c|c|}
\hline Variables & Unit & Value & SD \\
\hline Age (years) & Mean/SD & 49.43 & 18.9 \\
\hline Sex: Male & Percent & 65.1 & \\
\hline Female & Percent & 34.9 & \\
\hline \multicolumn{4}{|l|}{ Cause of Hospitalization } \\
\hline Surgical & Percent & 30.4 & \\
\hline Medical & Percent & 69.6 & \\
\hline Length of hospital stay(days) & Mean/SD & 14.7 & 11.6 \\
\hline Length of ICU stay(days) & Mean/SD & 7.6 & 6.4 \\
\hline Mechanical Ventilation & Percent & 85.9 & \\
\hline Inotropic support & Percent & 52.4 & \\
\hline APACHE II & Mean/SD & 19.30 & 7.01 \\
\hline \multicolumn{4}{|l|}{ Acute Kidney injury } \\
\hline AKIN & Percent & 85.8 & \\
\hline RIFLE & Percent & 81.4 & \\
\hline \multicolumn{4}{|l|}{ Treatment (number) } \\
\hline Conservative & & 209 & \\
\hline Renal replacement therapy & & 92 & \\
\hline SLED & & 50 & \\
\hline Regular & & 42 & \\
\hline Actual Death & Percent & 25 & \\
\hline $\begin{array}{l}\text { Left against medical } \\
\text { advice(LAMA) }\end{array}$ & Percent & 29.7 & \\
\hline Total assumed Mortality* & Percent & 54.7 & \\
\hline
\end{tabular}

*Patient went LAMA were sick and they were assumed to have expired at home or at another center

Table 1 shows Male: Female- 65.1: 34.9; 69.4\% were medical vs $30.6 \%$ surgical patients. Mean length of ICU and hospital stay was $7.6 \pm 6.4$ and $14.6 \pm 11.6$ days respectively. $85.9 \%$ subjects required ventilatory support and $52.4 \%$ required inotropic support. AKI in $85.8 \%$ subjects by AKIN and $81.4 \%$ by RIFLE criteria. The total assumed mortality was $54.7 \%$.

TABLE 2: Baseline characteristics of patients as per RIFLE criterion

\begin{tabular}{|c|c|c|c|c|c|c|c|c|c|}
\hline Variable & \multicolumn{2}{|c|}{ No AKI } & \multicolumn{2}{c|}{ Risk } & \multicolumn{2}{c|}{ Injury } & \multicolumn{2}{c|}{ Failure } & $\begin{array}{c}\text { p- } \\
\text { value }\end{array}$ \\
\hline $\begin{array}{c}\text { Age } \\
\text { (Mean/SD) }\end{array}$ & 44.49 & 17.90 & 50.25 & 18.85 & 51.42 & 20.18 & 51.05 & 18.03 & 0.084 \\
\hline $\begin{array}{c}\text { Male } \\
\text { (No./\%age) }\end{array}$ & 43 & 64.18 & 46 & 67.65 & 61 & 66.30 & 86 & 64.66 & 0.968 \\
\hline $\begin{array}{c}\text { Urea } \\
\text { (Mean/SD) }\end{array}$ & 37.67 & 19.97 & 45.18 & 24.14 & 57.49 & 33.03 & 85.04 & 59.21 & $\mathbf{0 . 0 0 0}$ \\
\hline $\begin{array}{c}\text { Cr. Day 1 } \\
\text { (Mean/SD) }\end{array}$ & 0.93 & 0.32 & 1.07 & 0.41 & 1.42 & 0.64 & 2.46 & 1.94 & $\mathbf{0 . 0 0 0}$ \\
\hline $\begin{array}{c}\text { Urine output } \\
\text { Day 1 } \\
\text { (Mean/SD) }\end{array}$ & 1683. & 965.2 & 1552. & 799.2 & 1564. & 833.7 & 920.5 & 662.93 & $\mathbf{0 . 0 0 0}$ \\
\hline $\begin{array}{c}\text { Mortality at } \\
\text { discharge } \\
\text { hospital } \\
\text { (No./\%age) }\end{array}$ & 4 & 7.41 & 11 & 18.97 & 17 & 22.08 & 56 & 48.70 & $\mathbf{0 . 0 0 0}$ \\
\hline
\end{tabular}

Table 3: Baseline characteristics of patients as per AKIN criterion

\begin{tabular}{|c|c|c|c|c|c|}
\hline Variable & No AKI & Stage-1 & Stage-2 & Stage-3 & $\begin{array}{c}\text { p- } \\
\text { value }\end{array}$ \\
\hline
\end{tabular}

\begin{tabular}{|c|c|c|c|c|c|c|c|c|c|}
\hline $\begin{array}{c}\text { Age } \\
\text { (Mean/SD) }\end{array}$ & 43.76 & 18.23 & 50.37 & 19.01 & 51.66 & 20.51 & $\begin{array}{c}50.5 \\
1\end{array}$ & 17.56 & 0.097 \\
\hline $\begin{array}{c}\text { Male } \\
\text { (No./\%age) }\end{array}$ & 30 & 58.82 & 66 & 67.35 & 54 & 67.50 & 86 & 65.65 & 0.732 \\
\hline $\begin{array}{c}\text { Urea } \\
\text { (Mean/SD) }\end{array}$ & 34.40 & 18.66 & 51.12 & 29.80 & 55.35 & 33.28 & $\begin{array}{c}84.0 \\
0\end{array}$ & 58.87 & 0.000 \\
\hline $\begin{array}{c}\text { Cr. Day } 1 \\
\text { (Mean/SD) }\end{array}$ & 0.83 & 0.27 & 1.22 & 0.50 & 1.40 & 0.67 & 2.44 & 1.96 & 0.000 \\
\hline Urine & 1642.1 & 991.9 & 1568. & 801.8 & 1539 & 837.9 & 945. & 702.0 & 0.000 \\
\hline $\begin{array}{l}\text { output Day } \\
1 \text { (Mean/SD) }\end{array}$ & 5 & 9 & 31 & 9 & 78 & 8 & 75 & 5 & \\
\hline
\end{tabular}

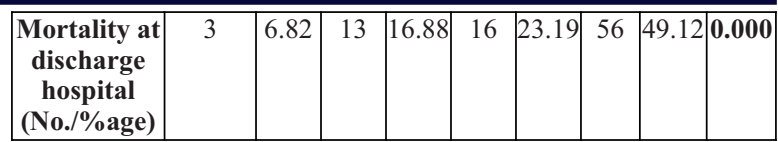

Table 2 \& 3 shows that subjects in non AKI group were comparatively younger than AKI subjects. Mortality was higher in AKI subjects compared to non AKI and also mortality increased with the severity of renal dysfunction.

\section{Mean APACHE II score in relation to the renal failure}

$\|$ AKI $=$ No AKI

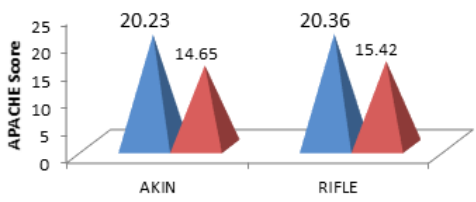

Figure 1

Figure 1 shows that mean APACHE II score was higher in AKI subjects compared to non AKI and was statistically significant ( $\mathrm{p}$ value $0.001)$

\section{Mean APACHE II score of subjects as per AKIN criteria}

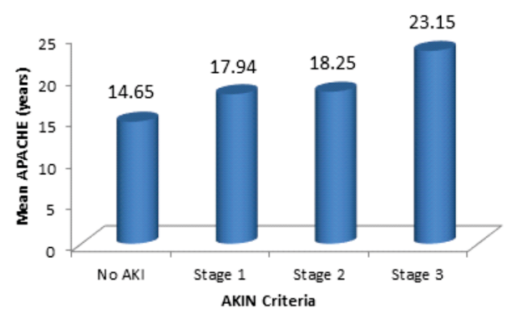

Figure 2

Figure 2 shows that mean APACHE II score increases with severity of AKIN staging.

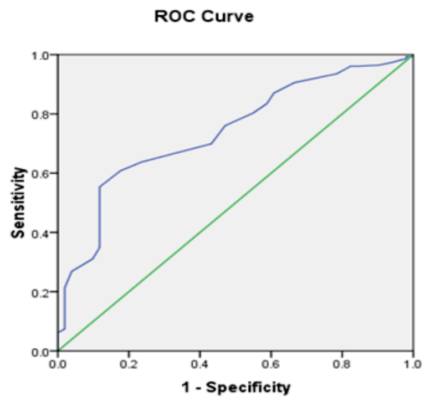

Diagonal segments are produced by ties.

Figure 3: ROC Curve-AKIN/APACHE II Score

Area under the Curve

Test Result Variable(s): APACHE II

Area: 0.739

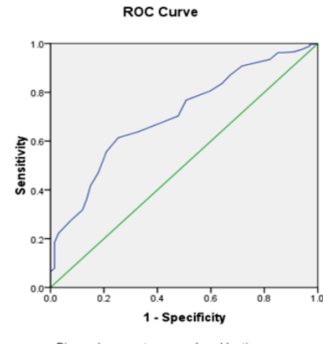

Figure 4 : ROC Curve- RIFLE/APACHE II score 


\section{Area under the Curve}

Test Result Variable(s): APACHE II

Area: 0.706

The Figure 3 and 4 show the area-under-ROC curves for APACHE II score in subjects diagnosed AKI by RIFLE and AKIN criteria respectively. The AUROC for APACHE II score was 0.739 and 0.706 for AKIN and RIFLE respectively. It signifies APACHE II score shows significant correlation with AKI.

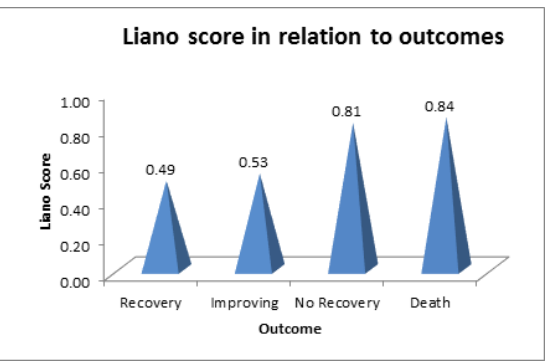

\section{Figure 5}

Figure 5 shows that subjects with high Liano score had higher probability of death and lesser chances of recovery which was statistically significant ( $\mathrm{p}$ value -0.021 )

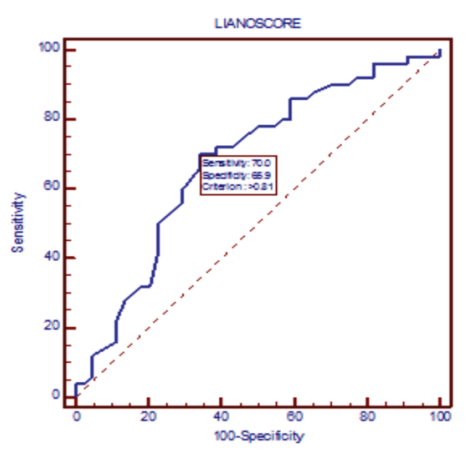

Figure 6 : ROC Curve- Mortality/Liano Score

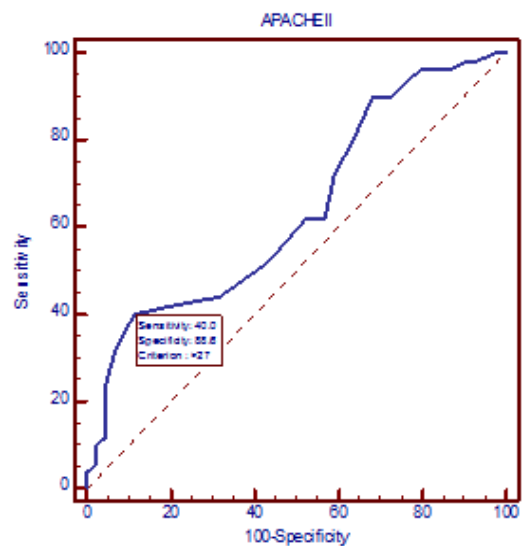

Figure 7 : ROC Curve-Mortality/APACHE II score

Table 7: APACHEII and Liano score for predicting Mortality

\begin{tabular}{|c|c|c|c|c|}
\hline & $\begin{array}{c}\text { Area under the } \\
\text { ROC curve (AUC) }\end{array}$ & $\begin{array}{c}\text { Standard } \\
\text { Error }\end{array}$ & $\begin{array}{c}\text { 95\% Confidence } \\
\text { interval }\end{array}$ & Palue \\
\hline APACH & 0.639318 & 0.0573 & 0.533751 to & 0.0151 \\
EII & & & 0.735847 & \\
\hline LIANO & 0.677727 & 0.0565 & 0.573432 to & 0.0017 \\
SCORE & & & 0.770472 & \\
\hline
\end{tabular}

Table 8: Comparison of AUC of APACHEII and Liano score

\begin{tabular}{|c|c|c|c|}
\hline & Difference & $\begin{array}{c}\text { Standard } \\
\text { Error }\end{array}$ & P value \\
\hline $\begin{array}{c}\text { Comparison of AUC of } \\
\text { APACHEII and LIANOSCORE }\end{array}$ & -0.038409 & 0.0805 & 0.6331 \\
\hline
\end{tabular}

Table $7 \& 8$ and Figure $6 \& 7$ shows that AUROC was 0.677 and 0.639 for Liano and APACHE II score respectively. Their AUC on comparison showed insignificant $p$ value $(0.6331)$. Both scores discrimination was equally poor.

Table 9: Hosmer \& Lemeshow test of the goodness of fit for APACHE II and Liano score

\begin{tabular}{|c|c|c|c|c|c|c|c|c|c|}
\hline & \multicolumn{7}{|c|}{$95 \%$ C.I.for odds ratio } \\
\hline & $\begin{array}{c}\text { Chi- } \\
\text { square }\end{array}$ & df & $\begin{array}{c}\text { P value for } \\
\text { goodness of fit }\end{array}$ & B & S.E. & $\begin{array}{c}\text { P } \\
\text { value }\end{array}$ & $\begin{array}{c}\text { Odds } \\
\text { ratio }\end{array}$ & Lower & Upper \\
\hline $\begin{array}{c}\text { APAC } \\
\text { HE II }\end{array}$ & 15.581 & 7 & 0.029 & .091 & .035 & 0.010 & 1.095 & 1.021 & 1.173 \\
$\begin{array}{c}\text { Liano } \\
\text { S }\end{array}$ & 2.821 & 8 & 0.945 & 3.351 & 1.223 & 0.006 & 28.537 & 2.595 & 313.789 \\
\hline
\end{tabular}

Table 9 shows that with the increase in APACHE II by 1 unit, the risk of mortality increases with odds ratio of 1.095 while the increase in Liano Score by 1 unit, the risk of mortality increases with odds ratio of 28.537. Hosmer \& Lemeshow test of the goodness of fitness suggests that model is a good fit to the data as $\mathrm{p}=0.945(>.05)$ for LIANO Score and not a good fit for APACHE II to the data as $\mathrm{p}=0.029(<.05)$.

\section{DISCUSSION}

In this study, $70 \%$ were medical patients, $85.9 \%$ required mechanical ventilation and mean length of stay in ICU was 7.6 days [Table1]. In a large multinational, multicenter prospective study of acute kidney injury in critically ill patients (BEST Kidney investigators) $60 \%$ were medical patients, $85 \%$ patients required mechanical ventilation, and mean length of stay in ICU was 16 days ${ }^{[7]}$.

Patients with AKI had a longer ICU length of stay ( $8.2 \pm 6.8$ days) compared to patients without AKI $(5.3 \pm 2.8$ days $)$. Patients with Failure/Stage 3 AKI had a shorter length of stay probably due to higher mortality associated with Failure/Stage 3 .

In general, the prognostic models developed as from an overall population of ICU patients have an unsatisfactory performance, when tested in a more specific population ${ }^{[8]}$. General prognostic scores, APACHE II, SOFA and SAPS II, are the most widely used models for the evaluation of severity of patients admitted in ICU. The APACHE II score seems to underestimate mortality in ARF patients when calculated on the day of the first dialysis ${ }^{[2,9]}$.

The beginning and ending supportive therapy for the kidney (BEST Kidney) study ${ }^{[8]}$ which included more than 1,742 patients from 54 centers, tested and compared six scoring systems; in their international sample, none of these had an area under receiver operating characteristics (ROC) curve above the conventional threshold of 0.7 that is typically considered satisfactory for clinical use. Among the scoring systems the group tested, they found the Liano score to have the best discrimination and calibration.

We found that on first day of ICU admission mean APACHE II score in patients with AKI was higher (20.2 \pm 6.9$)$ compared to non AKI (14.65 \pm 5.58 ) and was statistically significant (p- 0.001) [Table 4]. APACHE II also showed association with severity of renal dysfunction (17.94 -Stage 1; 18.25-Stage 2; 23.15-Stage 3). Also high mean APACHE II score was associated with increased mortality.

We observed that subjects with high mean Liano score had high probability of death $(0.8 \pm 0.17)$ and less recovery $(0.81 \pm 0.16)$ compared to subjects which were improving $(0.49 \pm 0.17)$ and it was statistically significant $(\mathrm{p}=0.021)$ [Table 6].

Assessment of prognostic models for mortality was made through analysis of the discrimination and calibration. In our prognostic models, the AUROC was 0.677 for the Liano score and 0.639 for the APACHE II score [Table $7 \& 8$ ]. Discrimination was equally poor in both models. The goodness of fit test for Laino and APACHE II showed that calibration was good for specific model. [Table 9] In a study by Uchino ${ }^{[10]}$, performance of four specific models for AKI (Mehta, Paganini, Chertow and Liano), in addition to the SAPS II and SOFA scores, were studied. Study showed discrimination was equally poor for all models with AUROC ranging from 0.610 for the Chertow score and 0.698 for the Liano score.

A study by Batista ${ }^{[1]}$ evaluated the APACHE II and the Liano model. Discrimination was reasonable for the two models (AUROC of 0.76 
and 0.78 respectively) but calibration was good only for the specific model. Another study by D'Avila ${ }^{[12]}$ carried out on APACHE II and Liano scores showed that discrimination was better for the specific score $(\mathrm{AUROC}=0.81$ versus $\mathrm{AUROC}=0.65)$.

Our study showed poor discrimination but good calibration for renal specific score, similar to Batista et al, (2004).

Earlier studies showing poor discrimination thought that the number of patients evaluated in a study may change the outcome however Zhu ${ }^{[13]}$ assessed the influence of sample size when analyzing the performance of the Mortality Probability Models (MPM) II using computer simulations and the authors proved that the smaller size of the sample, does not affect the evaluation of the model's discrimination.

Differences in the mortality rate among units may also be responsible for differences in the performance of prognostic models. In general, these scores were developed to predict mortality in populations in which the majority of patients had low probability of death. Therefore, the use of these prognostic models in patients with ARF, whose mortality rate is high, may decrease their efficacy.

Different inclusion criteria or ARF definition than those from the original studies may directly influence model performance. Scores developed at one institution do not necessarily have a good performance when validated in other institutions ${ }^{[2]}$. Although the ARF-specific scoring method had good calibration but discrimination was poor. Therefore, a specific model is still warranted for the design of clinical trials, for comparison studies and for prediction of outcomes in ARF patients, especially those in the ICU.

\section{CONCLUSION}

On assessment of performance of both the prognostic scores APACHE II and Liano had poor discrimination but calibration was good for Liano model.

\section{REFERENCES}

1. Mahajan S, Tiwari S, Bharani R, Bhowmik D, Ravi S, Agarwal SK, et al. Spectrum of acute renal failure and factors predicting its outcome in an intensive care unit in India. acute renal failure and

2. Halstenberg WK, Goormastic M, Paganini EP: Validity of four models for predicting outcome in critically ill acute renal failure patients. Clin Nephrol.1997;47 (2):81-6.

3. Lins RL, Elseviers M, Daelemans R, Zachée P, Gheuens E, Lens S, et al. Prognostic value of a new scoring system for hospital mortality in acute renal failure. Clin Nephrol 2000; $53: 10-7$.

4. Knaus WA, Wagner DP, Draper EA, Zimmerman JE, Bergner M, Bastos PG, et al. The APACHE III prognostic system. Risk prediction of hospital mortality for critically ill hospitalized adults. Chest 1991, 100,1619-36.

5. Parker RA, Himmelfarb J, Tolkoff-Rubin N, Chandran P, Wingard RL, Hakim RM. Prognosis of patients with acute renal failure requiring dialysis: results of a multicenter Prognosis of patients with acute renal failure requiring dialysis: results of a multicenter
study. Am J Kidney Dis. 1998 Sep;32(3):432-43. study. Am J Kidney Dis. 1998 Sep;32(3):432-43

6. Lian $\sim$ F, Pascual J. Acute renal failure, critical illness and the artificial kidney: can we predict outcome? Blood Purif. 1997; 15:346-53

7. Bagshaw SM, Uchino S, Bellomo R, Morimatsu H, Morgera S, Schetz M, et al. Septic acute kidney injury in critically ill patients: Clinical characteristics and outcomes. Clin J Am Soc Nephrol. 2007 May;2(3):431-9. Epub 2007 Mar 21.

8. Elizabeth R. Maccariello; Carla Valente; Lina Nogueira; Ricardo V. R. Valença; Márcio Soares, et al. Performance of six prognostic scores in critically ill patients receiving renal replacement therapy: Rev. bras. ter. intensiva vol.20 no. 2 São Paulo Apr./June 2008

9. Mehta RL, Pascual MT, Gruta CG, Zhuang S, Chertow GM. Refining predictive models in critically ill patients with acute renal failure. Jam Soc Nephrol. 2002;13:1350-7.

10. Uchino S, Kellum JA, Bellomo R, Doig GS, Morimatsu H, Morgera S, et al. Acute renal failure in critically ill patients: A multinational, multicenter study. JAMA 2005;294:813-8

11. Batista PB, Cendorogolo Neto M, dos Santos OF, Carvalho Bacelar AC, Batista Campos G, dos Santos ES. Evaluation of prognostic indexes in critical acute renal failure patients. Ren Fail,2004;26:545-52.

12. d'Avila DO, Cendoroglo Neto M, dos Santos OF, Poli de Figueiredo CE. Acute renal failure needing dialysis in the intensive care unit and prognostic scores. Ren Fail, 2004;26:59-68.

13. Zhu BP, Lemeshow S, Hosmer DW, Klar J, Avrunin J, Teres D. Factors affecting the performance of the models in the Mortality Probability Model II system and strategies of customization: a simulation study. Crit Care Med, 1996;24:57-63. 